\title{
DEVELOPMENT AND CHARACTERISATION OF NATURAL RUBBER - GELATIN BLENDS WITH IMPROVED BIODEGRADABILITY
}

\author{
Gean A Varghese \\ Department of Polymer Science and Rubber Technology, Cochin University of Science \& \\ Technology, Kochi, Kerala, 682022, India \\ Department of Chemistry, St. Peter's College, Kolenchery, Ernakulam, Kerala, 682311, India
}

\section{Bipinbal P K}

Department of Polymer Science and Rubber Technology, Cochin University of Science \& Technology, Kochi, Kerala, 682022, India

\section{Dileep P}

Department of Polymer Science and Rubber Technology, Cochin University of Science \& Technology, Kochi, Kerala, 682022, India

\section{Eby Thomas Thachil}

Department of Polymer Science and Rubber Technology, Cochin University of Science \& Technology, Kochi, Kerala, 682022, India

\section{Sunil K Narayanankutty}

Department of Polymer Science and Rubber Technology, Cochin University of Science \& Technology, Kochi, Kerala, 682022, India

\begin{abstract}
Natural rubber (NR) blends with different concentrations of gelatin (GLN) were successfully prepared through solution casting and dry-mixing techniques. The gelatin content was varied from 0 to $20 \mathrm{phr}$. The blends were cured at $150{ }^{\circ} \mathrm{C}$ to their respective optimum cure times. Biodegradability was evaluated using soil burial test and was found to have improved with gelatin content. A gelatin loading of $10 \mathrm{phr}$ was sufficient to impart a significant extent of biodegradation. The blends were also investigated for mechanical and dynamic mechanical properties, morphology and thermal and solvent resistance. Enhanced cure rate, increased cross-link density and improved mechanical properties, without any deterioration in thermal stability, could be achieved through the blending process. The blend realizes fabrication of a biodegradable substitute for vulcanized natural rubber without compromising mechanical and thermal properties.
\end{abstract}

Key words: natural rubber, gelatin, solution casting, bioblends, biodegradability. 
Cite this Article: Gean A Varghese, Bipinbal P K, Dileep P, Eby Thomas Thachil and Sunil K Narayanankutty, Development and Characterisation of Natural Rubber - Gelatin Blends with Improved Biodegradability, International Journal of Advanced Research in Engineering and Technology, 10 (3), 2019, pp 69-80.

http://iaeme.com/Home/issue/IJARET?Volume $=10 \&$ Issue $=3$

\section{INTRODUCTION}

Challenges posed by the use of non-biodegradable polymers on environment led to intense research on biodegradable materials from renewable resources. Gelatin is a material being used widely in this context on account of its abundance and low cost. Conventionally it has been used in food industry to improve elasticity, consistency and stability. Gelatin is an edible protein containing 18 amino acids with glycine as principle component [1]. It is extracted from collagen contained in the skins [2], bones [3] and conjunctive tissues of animals [4] and fishes and also from insects [5]. The raw materials are demineralised to get ossein, which on acid or alkali treatment gives Type A or Type B gelatin respectively [6]. According to the source material and processing conditions gelatin exhibits wide range of molecular weights which is reflected in its gel (bloom) strength [7]. Application of gelatin as a biomaterial is limited due to its inferior mechanical properties. However, its properties can be improved by combining with other polymers. Blending [8], [9], grafting [10] and preparation of composites [11] are common methods employed to enhance the physical properties of gelatin. Covalent attachment of oxidized linoleic acid was found to be effective in improving the mechanical properties of GLN film [12]. Blending with polyvinyl alcohol (PVA) imparts higher thermal stability to gelatin scraps due to the shielding effect promoted by PVA [13]. In another instance thermal stability of gelatin was improved by blending it with ethyl cellulose through electrospinning method [14]. The functional groups of gelatin combine with green tea extract and form hydrogen bonds which resulted in better water barrier and mechanical properties of the film [15]. Crosslinking could be employed as a mean to alter mechanical and thermal characteristics of gelatin. Gelatin develops covalent cross-links when water content was reduced to about $0.2 \mathrm{~g} / 100 \mathrm{~g}$ of protein [16]. Glutaraldehyde can be used as an external crosslinker to improve the thermal and mechanical properties of gelatin films [11]. Without modification also gelatin finds immense potential for application, the most important one being its use as a modifier in other polymer matrices to improve biodegrdability.

Natural rubber is the most versatile elastomer obtained from a renewable source, finding application in a variety of fields. It is of utmost importance to find ways for enhancing biodegradability of natural rubber products. With this objective, different biodegradable components have been tried in the natural rubber matrix [17]. Gelatin, due to its biodegradability, low cost and easy availability is a suitable candidate for use in natural rubber [18]. Composites of gelatin with natural or synthetic biopolymers were used for the production of scaffolds for ocular applications [13]. Gelatin has been used in Nitrile rubber to improve tensile strength and abrasion resistance [19]. Addition of sugarcane bagasse on unvulcanised GLN/NR blend increased $60 \%$ biodegradability and further addition of urea resulted in $65-70 \%$ biodegradability [20]. A composite of unvulcanized NR with gelatin was prepared by Sukhlaaied et al. using potassium persulfate as an initiator in an aqueous latex solution [8]. The grafts of NR on gelatin present in the composite improved tensile strength, elongation at break and water resistance of the resultant film [8]. However it is well known that natural rubber can be commercially exploited only through the process of vulcanization. To the best of our knowledge, there has been no studies on the effect of gelatin on vulcanized natural rubber. This study explores vulcanized natural rubber/gelatin blends prepared through two different processing methods. 
The current work is to improve biodegradability of natural rubber by combining with gelatin without compromising the advantages of natural rubber. Here we report the mechanical, dynamic mechanical, thermal and barrier properties of NR blends with different GLN content. These bio-blends find applications in food packaging and medical materials.

\section{MATERIALS AND METHODS}

\subsection{Raw materials}

Natural Rubber latex (60\% DRC) was purchased from Njavallil latex pvt., Ltd. Ernakulam, India. Gelatin (type B) with bloom strength of approximately 225 was obtained from Merck India Ltd. All other rubber ingredients zinc oxide ( $\mathrm{ZnO})$, stearic acid, 1,2-dihydro2,2,4trimethylquinoline (TQ), N-cyclohexyl-2-benzothiazole sulphenamide (CBS), Zinc-2mercaptobenzothiazole (ZMBT), Zinc diethyldithiocarbamate (ZDC), Titanium dioxide $\left(\mathrm{TiO}_{2}\right)$, Wingstay $\mathrm{L}, \mathrm{KOH}$ and sulphur (S) were of commercial grades and is used as received.

\subsection{Methods}

\subsubsection{Preparation of NR/GLN blends by solution casting}

$167 \mathrm{~g}$ of NR latex was de-ammoniated by stirring in a mechanical stirrer for 30 minutes. A solution of $5 \%(\mathrm{w} / \mathrm{w}) \mathrm{GLN}$ in distilled water at $50^{\circ} \mathrm{C}$ was prepared using a magnetic stirrer. The latex was then mixed with appropriate quantity of GLN so as to obtain a GLN composition of 5-20 phr. The mixture was stirred continuously for 15 minutes followed by the addition of compounding ingredients in the form of dispersion as per the formulation in Table 2.1. After 20 minutes of continuous stirring to obtain a homogeneous consistency, the mixture was poured into a glass tray. It was dried to a sheet by keeping the tray in a hot air oven at $60{ }^{\circ} \mathrm{C}$ for 24 hours. It was then heated at $100{ }^{\circ} \mathrm{C}$ for 3 hours for the completion of curing reaction. The dried sheets were used for property evaluation.

\subsubsection{Preparation of NR/GLN blends by compression moulding}

$167 \mathrm{~g}$ of NR latex was de-ammoniated by continuous stirring in a mechanical stirrer for 30 minutes. A solution of $5 \%(\mathrm{w} / \mathrm{w}) \mathrm{GLN}$ in distilled water at $50{ }^{\circ} \mathrm{C}$ was prepared using a magnetic stirrer. The latex was then mixed with appropriate quantity of GLN so as to obtain a GLN composition of 5-20 phr. The mixture was then poured into a glass tray and kept in hot air oven for 24 hours at $60{ }^{\circ} \mathrm{C}$. The dried film was then compounded according to ASTM D 3184 as per the formulation given in Table 2.2 on a Thermo Haake Polylab (QC Version 1.02), an internal mixer equipped with Banbury rotors, at $60{ }^{\circ} \mathrm{C}$ and $60 \mathrm{rpm}$. NR/GLN dry film was masticated for 3 minutes for molecular break down, followed which $\mathrm{ZnO}$ and stearic acid were added. After 2 minutes TQ, CBS and Sulphur were added in that order and mixed. Mixing was continued for 2 more minutes to get a homogeneous distribution of all ingredients in NR. After mixing, the compound was rolled and passed endwise 6 times through tight nip gap on a laboratory two-roll mixing mill (size 6"x12") and finally sheeted out at a nip gap of $3 \mathrm{~mm}$. The compound was kept at room temperature for 24 hours for maturation. The cure time was determined in a rheometer (RPA 2000) using approximately $5 \mathrm{~cm}^{3}$ of sample punched into a circular disc. The test specimens were vulcanized at $150{ }^{\circ} \mathrm{C}$ to their optimum cure times in standard moulds by compression moulding using an electrically heated hydraulic press with $12^{\prime \prime} 12^{\prime \prime}$ platen size at a pressure of $15 \mathrm{MPa}$.

Table 2.1 Formulation of NR/GLN blends for solution casting

\begin{tabular}{|l|c|}
\hline \multicolumn{1}{|c|}{ Ingredients } & Parts per hundred rubber \\
\hline NR Latex & 100 \\
\hline Gelatin & $0-20$ \\
\hline
\end{tabular}


Gean A Varghese, Bipinbal P K, Dileep P, Eby Thomas Thachil and Sunil K Narayanankutty

\begin{tabular}{|l|c|}
\hline Sulfur & 1.1 \\
\hline Zinc oxide & 0.35 \\
\hline ZMBT & 0.2 \\
\hline ZDEC & 0.85 \\
\hline $\mathrm{TiO}_{2}$ & 0.25 \\
\hline Wingstav L & 0.75 \\
\hline $\mathrm{KOH}$ & 0.15 \\
\hline
\end{tabular}

Table.2.2 Formulation of NR/GLN blends for dry-mixing

\begin{tabular}{|l|c|}
\hline \multicolumn{1}{|c|}{ Ingredients } & Parts per hundred rubber \\
\hline NR latex & 100 \\
\hline Gelatin & $0-20$ \\
\hline Sulphur & 2.5 \\
\hline ZnO & 4 \\
\hline Stearic acid & 2 \\
\hline TO & 1 \\
\hline CBS & 1 \\
\hline
\end{tabular}

\subsection{Characterizations}

Cure characteristics of the dry mixes were determined using Rubber Process Analyser, RPA 2000 as per ASTM D 5289. Stress- strain tests were carried on a Shimadzu Model AGI Universal Testing Machine according to ASTM D 412. Tear resistance of the samples was tested as per ASTM D 624 using un-nicked $90^{\circ}$ angle test specimen. Thermogravimetric analysis was performed on Thermogravimetric Analyzer Q-50, TA instruments with a heating rate of $20^{\circ} \mathrm{C} / \mathrm{min}$ under nitrogen atmosphere. Differential scanning calorimetry of the blends was performed on DSC Q100 of TA instruments. DMA Q800, TA instruments was used for dynamic mechanical analysis of the samples in tension mode. The fracture surfaces of the samples were examined with JOEL JSM 8390 LV scanning microscope. The biodegradation of the GLN/NR blends in soil was obtained according to Eq. (1).

$\%$ Biodegradation $=\frac{(\mathrm{T} 1-\mathrm{T} 2)}{\mathrm{T} 1} \times 100$.

Where, $T_{1}$ is the initial tensile strength before biodegradation while $T_{2}$ is the tensile strength after biodegradation of the samples in soil. The crosslink density was calculated using FloryRehner equation [21]

$$
\text { Crosslink density } \quad v=1 / 2 \mathrm{M}_{\mathrm{c}}
$$

Where $M_{c}$ is the molar mass between successive cross links and is given by

$$
\mathrm{M}_{\mathrm{c}}=-\rho_{\mathrm{r}} \mathrm{V}_{\mathrm{s}} \mathrm{V}_{\mathrm{r}}^{1 / 3} / \ln \left(1-\mathrm{V}_{\mathrm{r}}\right)+\mathrm{V}_{\mathrm{r}}+\chi \mathrm{V}_{\mathrm{r}}^{2} \ldots \ldots
$$

Where, $\rho_{\mathrm{r}}$ is density of rubber $\left(0.94 \mathrm{~g} / \mathrm{cm}^{3}\right), V_{\mathrm{S}}$ is the solvent molar volume $\left(106.2 \mathrm{~cm}^{3} / \mathrm{mol}\right.$ for toluene), $\chi$ is the interaction parameter for NR and toluene and is taken as 0.3796 [22] and $V_{r}$ is the volume fraction of the rubber in the vulcanizate swollen to equilibrium, which was calculated using Ellis and Welding equation [23]

$$
\mathrm{V}_{\mathrm{r}}=(d-f \mathrm{w}) \rho_{\mathrm{r}}^{-1} /(d-f \mathrm{w}) \rho_{\mathrm{r}}^{-1}+\mathrm{A}_{\mathrm{s}} \rho_{\mathrm{s}}^{-1} \ldots \ldots . .
$$

Where $d$ is the deswollen weight, $f$ is the fraction of insoluble ingredients, $\rho_{S}$ is the density of solvent and $A_{s}$ is the weight of solvent at equilibrium swelling.

\section{RESULTS AND DISCUSSIONS}

\subsection{Cure characteristics of NR/GLN blends}

The variation of scorch time and cure time of the blends with gelatin content is given in Fig. 1 (a) \& (b), respectively. Both the parameters were found to decrease by the addition of $5 \mathrm{phr}$ 
gelatin. At this loading there is a $70 \%$ reduction in scorch time and $43 \%$ reduction in cure time of the blend compared to neat NR. When heated, gelatin is prone to disintegration with the evolution of basic amino acids and ammonia [24]. The basic nature of the degradation products accelerates the cure rate there by decreasing scorch time and cure time [25]. With the addition of more amount of gelatin the viscosity of the medium increases which in turn reduces the mobility of the sulphur and accelerators [26]. Due to the decrease in probability of effective interaction of sulphur with NR chains the time required for attaining optimum $(90 \%)$ crosslinking increases. This may be the reason for the increase in scorch time and cure time on further addition of gelatin. As an anomalous behaviour, differential torque $\left(\mathrm{M}_{\mathrm{H}}-\mathrm{M}_{\mathrm{L}}\right)$ values of the blends showed a decrease with the addition of gelatin. At the temperature of cure test gelatin is bound to get softened. This softening reflects in the decrease in differential torque as shown in Fig. 1(c). There is a $27 \%$ decrease in differential torque with the addition of 20 phr gelatin.
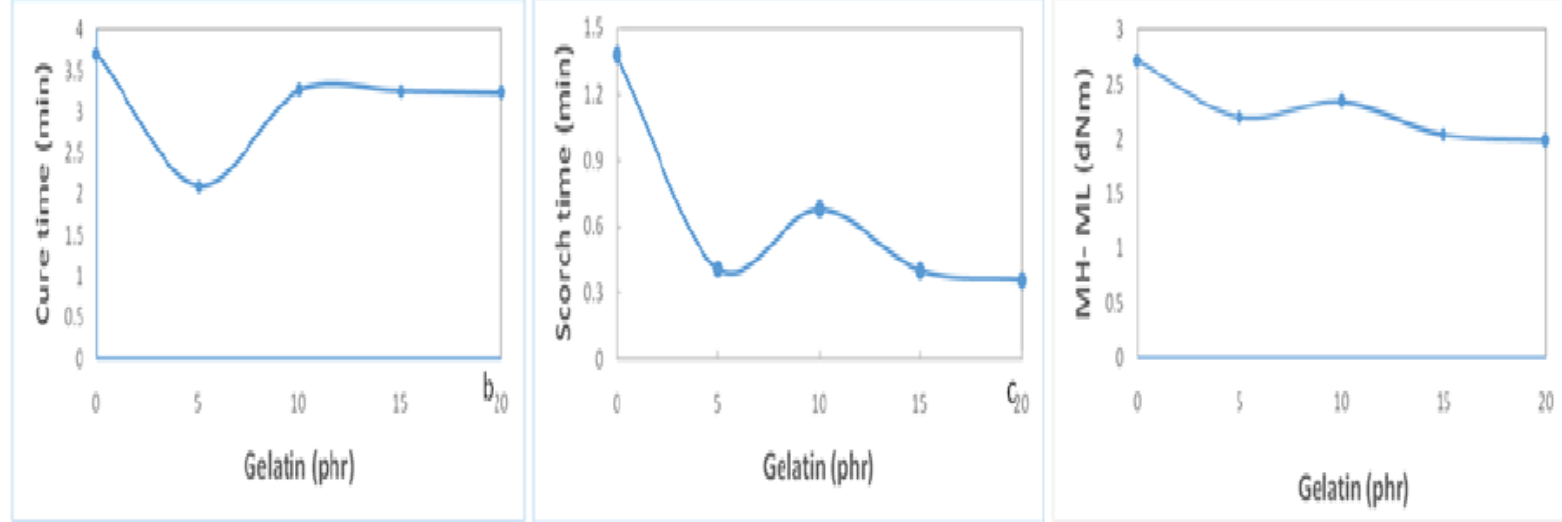

Figure 1 Cure characteristics of the samples: (a) scorch time (b) optimum cure time and (c) effective torque.

\subsection{Stress-strain properties of blends - Dry mixing and solution casting}

The influence of GLN on tensile strength, elongation at break and modulus at 300\% elongation of NR by dry mixing and solution casting is presented in Fig. 2. Both type of blends exhibited a decrease in tensile strength by the addition of 5 phr of gelatin. Gelatin containing a substantial amount of polar groups is inherently incompatible with the nonpolar natural rubber which leads to reduced interaction at the NR-gelatin interface and lower tensile strength. When gelatin content is increased further tensile strength also increases. This may be due to the formation of a continuous phase of gelatin at higher loadings which remain as an intertwined network with NR molecular chains. For both types of blends, $10 \mathrm{phr}$ gelatin loading imparts maximum tensile strength. For solution casted samples tensile strength shows a marginal improvement with higher loadings of gelatin, while in the case of dry mixed samples a decrease in the tensile strength is observed. This may be due to the difficulty in mixing process on account of the rigidity of gelatin at the dry mixing temperature. At higher loadings, due to improper mixing, there will be a nonhomogeneous distribution of gelatin in the rubber matrix which in turn leads to lower tensile properties. In the case of solution casting maximum tensile strength of 27.3 $\mathrm{MPa}$ was obtained for the blend containing 20phr GLN, where as a maximum of $37.2 \mathrm{MPa}$ could be realized for dry mixed samples at $10 \mathrm{phr}$ GLN loading. The curing is performed at higher temperature and pressure in the case of dry mixed blends compared to solution cast ones. This may bestow the dry mixed blends with higher number of crosslinks and improved mechanical properties, which reflects in the higher tensile strength of the blends. For both type of blends, the modulus at $300 \%$ elongation is increased while the elongation at break is decreased with increasing GLN content. These results are in good agreement with tensile 
strength of the blends. From the results it is found that compression moulding is more efficient method for NR/GLN blends compared to solution casting at lower loadings of gelatin.

(a)

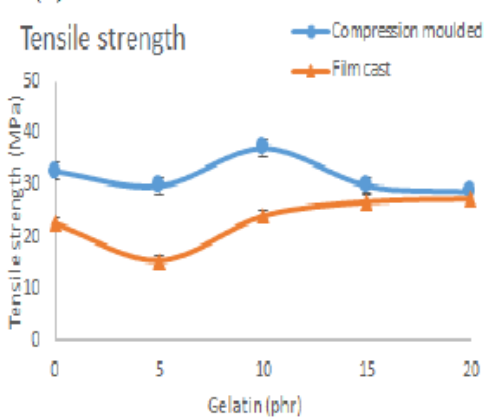

(b)

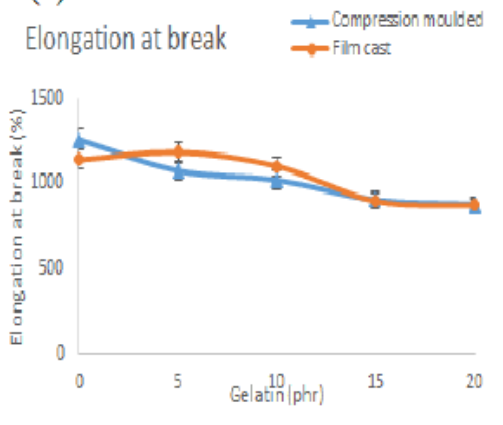

(c)

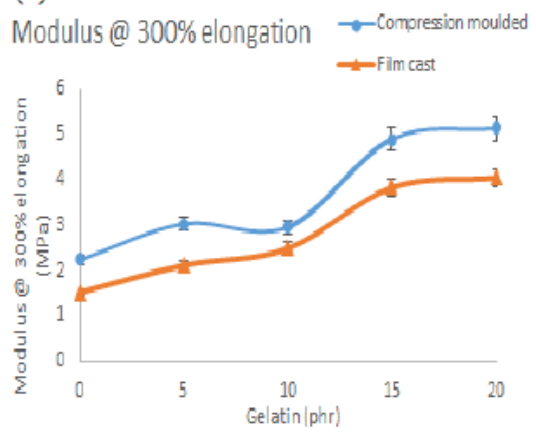

Figure 2 Stress-strain properties of the samples: (a) tensile strength (b) Elongation at break (c) Modulus at $300 \%$ elongation.

\subsection{Tear strength}

Tear strengths of NR/GLN blends are displayed in Fig. 4. For the dry mixed samples tear strength increased with the addition of $5 \mathrm{phr}$ GLN content and shows no significant change thereafter. The presence of gelatin phase dispersed within the rubber matrix hinders the crack propagation and increases the tear resistance of the blends. However at higher loadings there is no further increase in tear resistance. This can be attributed to the formation of a continuous and homogeneous gelatin phase through which crack propagation is comparatively easier than through the rubber phase. In the case of solution cast samples maximum tear strength is shown at $10 \mathrm{phr}$ loading of gelatin. The slight lowering of tear strength beyond this loading may be due to the emergence of the continuous gelatin phase which facilitates easier crack propagation.

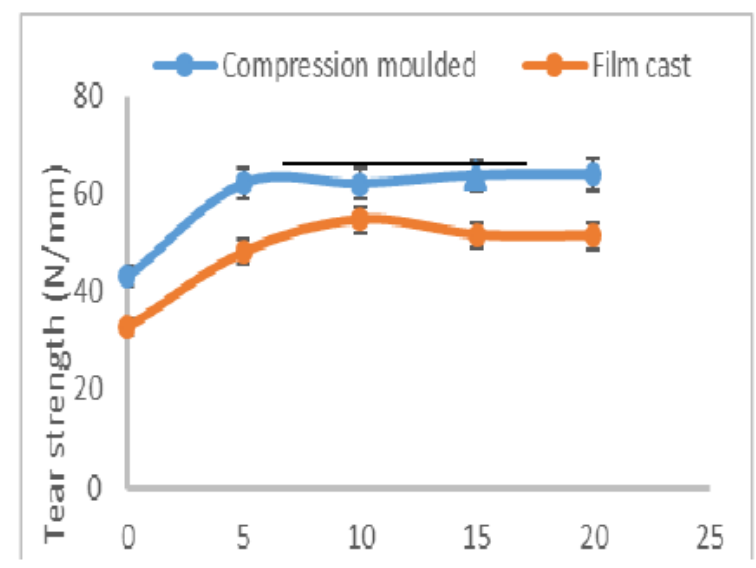

Figure 3 Tear strength of NR/GLN blends

\subsection{Scanning Electron Microscopy}

The SEM micrographs of the fractured sample surfaces of dry mixed and solution cast samples of NR/GLN blend vulcanizates are illustrated in Figs. 4 (a) and (b), respectively. The samples were frozen in liquid nitrogen and fractured. Dry mixed $10 \mathrm{phr}$ GLN sample surface shows continuous phases which are inter diffused, showing a homogeneous blending of NR and gelatin. Solution cast sample of $10 \mathrm{phr}$ GLN shows a random distribution of gelatin phases in the rubber matrix, suggesting improper mixing and poor GLN/NR interaction compared to dry mixed samples, which accounts for the lower mechanical properties. 
Development and Characterisation of Natural Rubber - Gelatin Blends with Improved Biodegradability
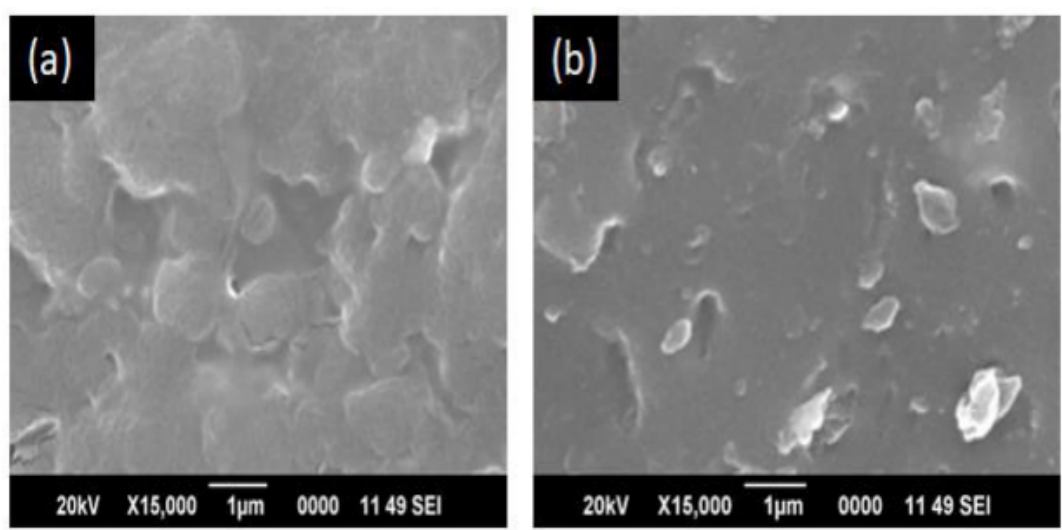

Figure 4 SEM images (a) dry mixed and (b) solution cast NR/GLN blend

\subsection{Thermogravimetric analysis}

Thermogravimetric analysis of dry mixed samples is shown in Fig. 5. 5(a) and 5(b) depicts TGA and DTG curves of the blends with neat NR and gelatin. It is evident from the figures that thermal stability of gelatin is lower compared to that of NR. Neat NR starts degradation around $300{ }^{\circ} \mathrm{C}$, while gelatin start to degrade around $220^{\circ} \mathrm{C}$. Incorporation of gelatin to NR decreases the thermal stability of NR. Degradation pattern of the blends is similar to that of neat NR, but the initial weight loss occures at lower temperature as can be seen from the TGA curves. Thermal stability is found to be decreasing in manner proportional to the amount of gelatin.

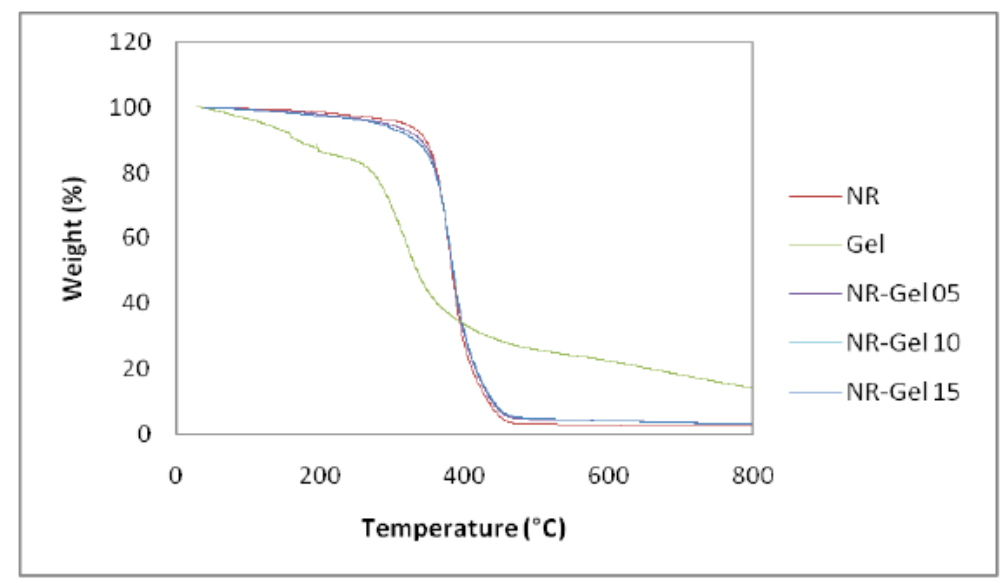

Figure 5(a) TGA curves of NR/GLN blends

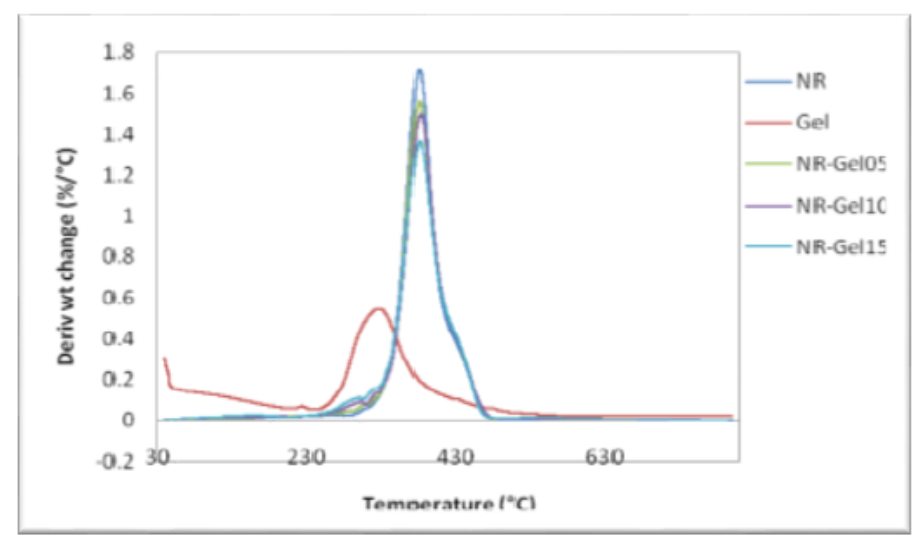

Figure 5(b) DTG curves of NR/GLN blends 


\subsection{Dynamic mechanical analysis}

The variation in storage modulus with frequency of solution cast and dry mixed blends is depicted in Figs. 6 (a) and (b), respectively. In both type of blends storage modulus show an improvement with gelatin content. Presence of gelatin restricts the segmental mobility of the natural rubber molecules thereby increasing the stiffness of the blends [27]. Storage modulus increases with the increase in test frequency. This may be attributed to the reduction in time for the rubber molecules to relax at high frequency, resulting in a stiffer response. The increase in storage modulus is more pronounced after a test frequency of $15 \mathrm{~Hz}$ especially for solution cast samples.
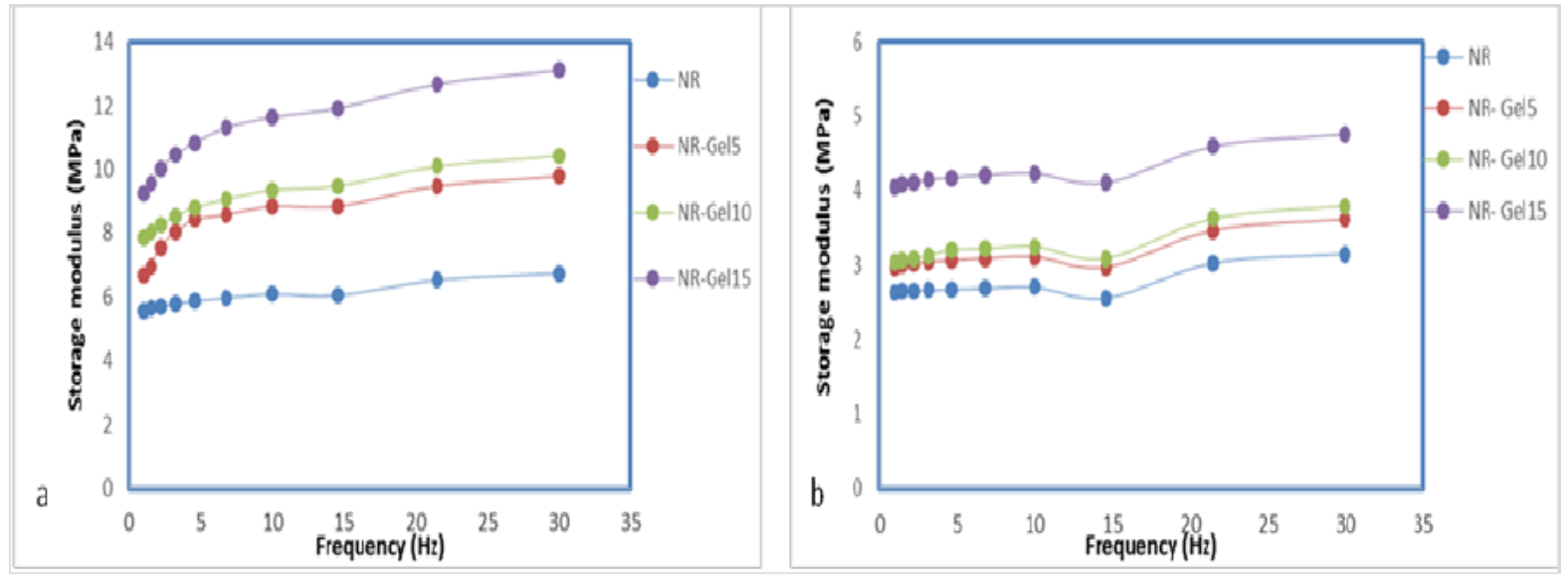

Figure 6 Storage modulus variation with frequency of (a) solution cast and (b) dry mixed GLN/NR blends

\subsection{Differential scanning calorimatry analysis}

Fig. 7 shows the DSC curves of NR and dry mixed GLN/NR blend with 10 phr gelatin content. The samples were conditioned at 50\% relative humidity since the adsorbed water in the hydrophilic gelatin influnces the properties of the samples. The glass transition temperature ( $T g$ ) of the blend shows a slight increase compared to NR. This can be attributed to the restriction in segmental mobility of NR imparted by the rigid gelatin molecules in the blend.

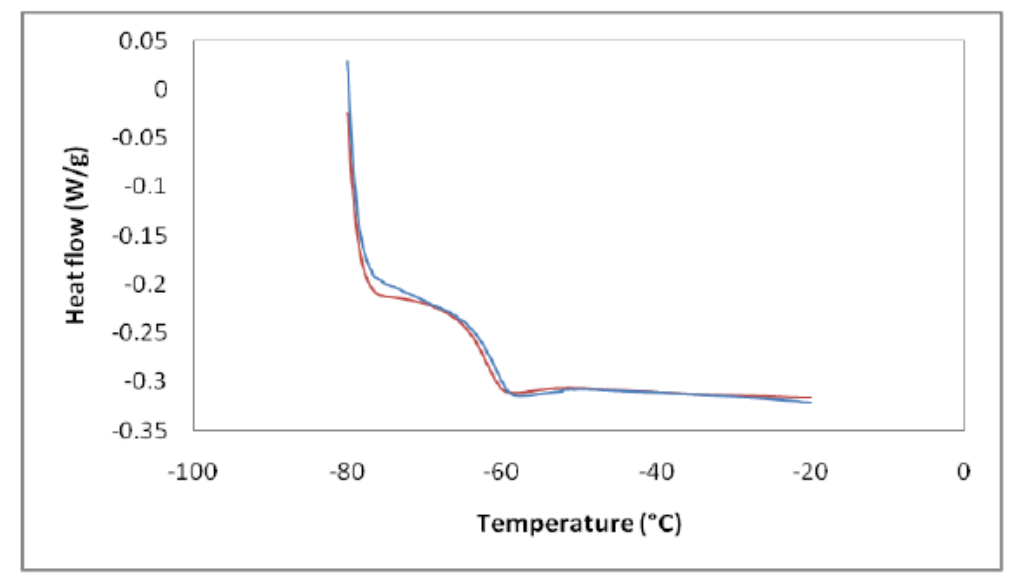

Figure 7 DSC curves of NR gum and $10 \mathrm{phr}$ GLN/NR blend

\subsection{Crosslink density}

Crosslink density of NR/GLN blends is plotted in Fig. 8 against gelatin content. Crosslink density of dry mixed samples is higher compared to that of solution cast samples. This can be 
attributed partly to the higher temperature and pressure employed during the curing of former. Also, as evident from SEM images, in the case of dry mixed samples, a continuous phase of gelatin found to be formed in the rubber matrix. The polar gelatin prevents the ingression of the nonpolar solvent into NR matrix. On the other hand solution cast samples with randomly distributed gelatin phases are not very effective in protecting the matrix from solvent intake, allowing the sample to swell to a higher degree and accordingly increasing the calculated crosslink density values based on swelling studies. For 15 and 20 phr solution cast samples an increase in crosslink density is observed which can be credited to the gelatin phase becoming more continuous. Mechanical properties also are in good agreement with the crosslink density values.

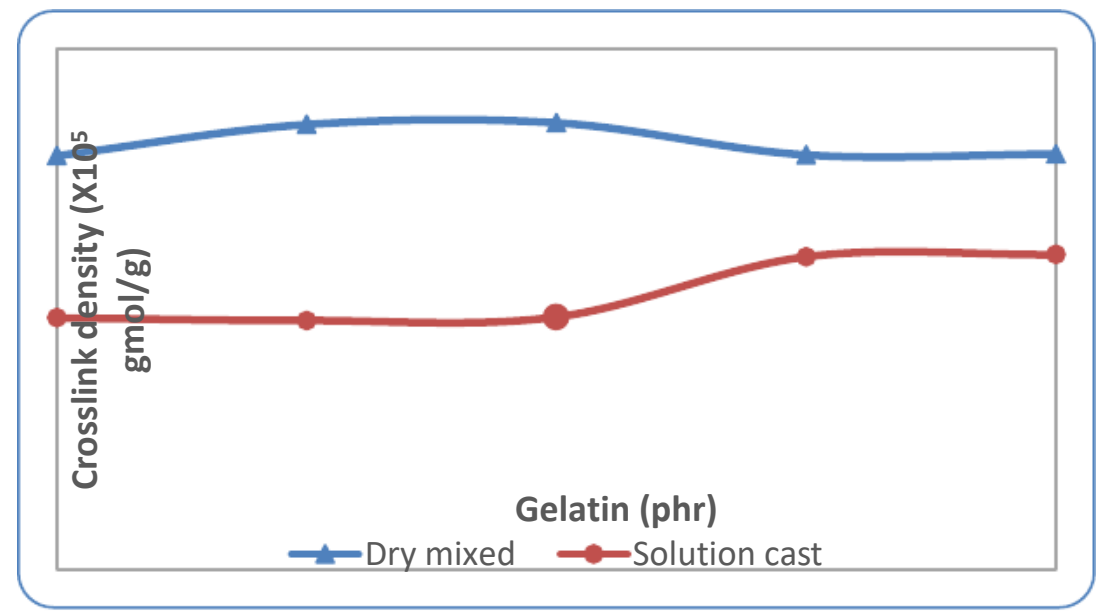

Figure 8 Crosslink density of NR/GLN blends.

\subsection{Biodegradation studies in soil}

Biodegradability studies on compression moulded and film casted NR/GLN samples were done by burying the samples in soil for 7 days. The tensile strength results of samples are shown in Fig. 9.

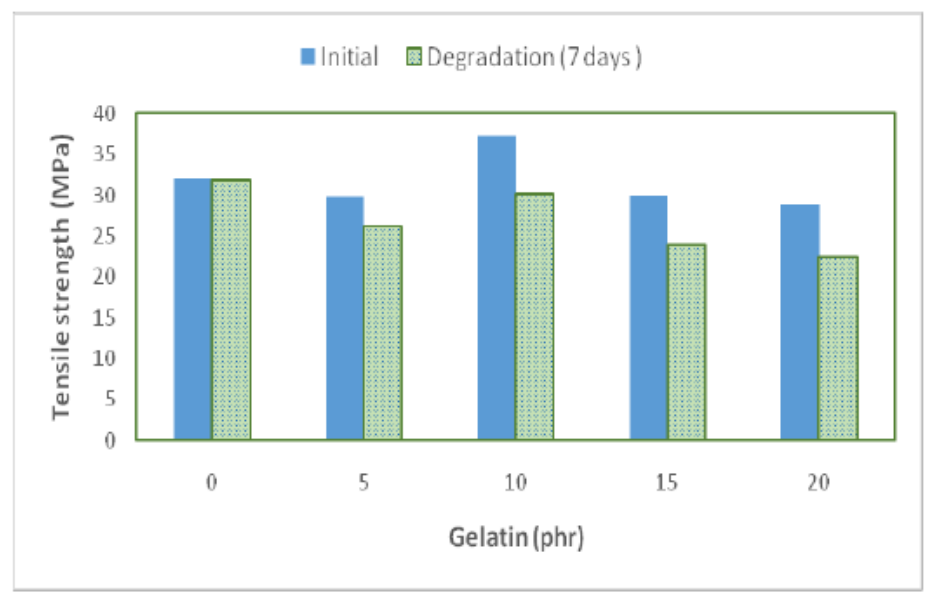

Figure 9(a) Reduction in tensile strength after soil burial test of dry mixed NR-GLN blends 


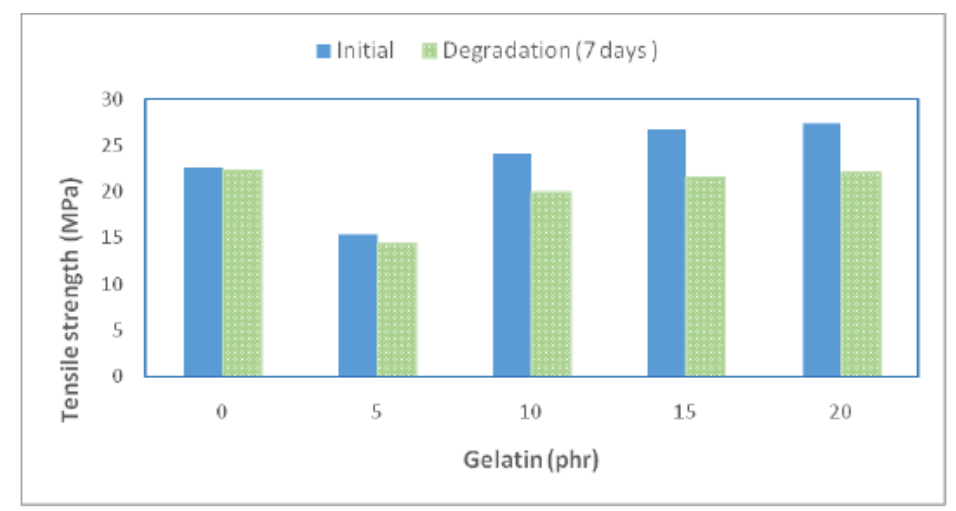

Figure 9(b) Reduction in tensile strength after soil burial test of solution cast NR-GLN blends

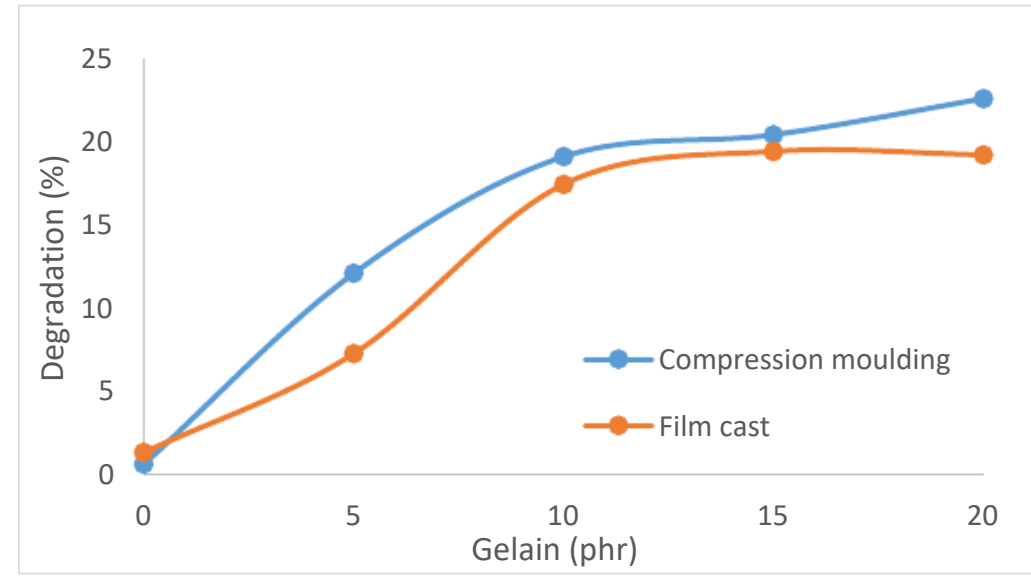

Figure 10 Percentage loss in tensile strength of NR-GLN blends

The loss in tensile strength after soil burial test for dry mixed and solution cast blends is shown in Figs. 9(a) and 9(b) respectively. In both the cases, blends containing gelatin show decrease in tensile strength after soil burial for 7 days. The loss in strength can be attributed to biodegradation of gelatin in the blends. The gelatin dispersed in the rubber matrix on degradation leaves cracks and voids inside the samples. On the application of a tensile force these cracks and voids act as points of stress concentration and eventually starting points of premature failure. Dry mixed blends show higher percentage degradation compared to solution cast samples (Fig. 10). Uniform distribution of gelatin in the rubber matrix in the case of dry mixed samples opens up more regions for biodegradation and consequently more defects in the rubber matrix. This is reflected as higher loss in strength of the material. With increase in gelatin content degradation also increases as evident from Fig. 10. Random distribution of gelatin phase in the solution cast samples reduces the area prone to biological degradation and lowers the loss in strength of the blends.

\section{CONCLUSION}

Natural Rubber (NR) was mixed with 0-20phr gelatin in two different methods, viz, dry mixing and solution casting, for the preparation of NR/GLN blends with improved biodegradability. Addition of gelatin reduces cure time and scorch time of the blends, but further additions increase the cure time due to increase in viscosity of the blends and resulting low mobility of curing agents. At curing temperatures gelatin imparts a plasticizing effect to the blend. Gelatin improves tensile properties by forming a continuous intertwined phase with the natural rubber matrix. The optimum concentration of gelatin in terms of mechanical properties was found to be $10 \mathrm{phr}$ for both dry mixing and solution cast blends. Dry mixed blend exhibited higher tensile 
Development and Characterisation of Natural Rubber - Gelatin Blends with Improved

Biodegradability

strength on account of higher crosslink density and gelatin forming of a continuous homogeneous phase with less defects. Thermal stability of the blends decreased with increase in gelatin content, while glass transition temperature slightly improved. Dry mixed blends showed higher crosslink density indicating more solvent resistance. The bio-blends are highly prone to biodegradation in soil, with dry mixed blends showing $23 \%$ loss in strength after 7 days of soil burial. Potential applications for these bioblends are envisaged in medical and food packaging industry.

\section{REFERENCES}

[1] Ward, A. G. (Alan G., and Courts, A. (Albert). The science and technology of gelatin. Academic Press. 1977.

[2] Bichukale, A. D., Koli, J. M., Sonavane, A. E., Vishwasrao, V. V., Pujari, K. H., and Shingare, P. E. Functional Properties of Gelatin Extracted from Poultry Skin and Bone Waste. International Journal of Pure \& Applied Bioscience, 6(4), 2018, pp. 87-101.

[3] Muyonga, J., Cole, C. G. and Duodu, K. Extraction and physico-chemical characterisation of Nile perch (Lates niloticus) skin and bone gelatin. Food Hydrocolloids, 18(4), 2004, pp. 581592.

[4] Avery, N. C., Sims, T. J., and Bailey, A. J. (2009). Quantitative Determination of Collagen Cross-links. In Methods in molecular biology (Clifton, N.J.) (Vol. 522, pp. 103-121).

[5] Mariod, A. A., and Fadul, H. Extraction and characterization of gelatin from two edible Sudanese insects and its applications in ice cream making. Food Science and Technology International, 21(5), 2015, pp. 380-391.

[6] Mariod, A. A., and Adam, H. F. Review: gelatin, source, extraction and industrial applications. Acta Scientiarum Polonorum Technologia Alimentaria, 12(2), 2013, pp. 135-147.

[7] Mark, H. F., Bikales, N. M., and Overberger, C. G. Encyclopedia of polymer science and technology. New York: Wiley Interscience. 1985.

[8] Sukhlaaied, W., and Riyajan, S.-A. A Novel Environmentally Compatible Bio-Based Product from Gelatin and Natural Rubber: Physical Properties. Journal of Polymers and the Environment, 26(7), 2018, pp. 2708-2719.

[9] Bertoldo, M., Coltelli, M.-B., Messina, T., Bronco, S., and Castelvetro, V. Emulsion Blending Approach for the Preparation of Gelatin/Poly (butylene succinate- co -adipate) Films. ACS Biomaterials Science \& Engineering, 2(4), 2016, pp. 677-686.

[10] Bertoldo, M., Cognigni, F., and Bronco, S. Preparation of gelatin/polyoxypropylene grafted copolymers by isocyanate promoted "grafting onto" reaction. Polymer, 53(21), 2012, pp. 4595 4603.

[11] Bigi, A., Cojazzi, G., Panzavolta, S., Rubini, K., and Roveri, N. Mechanical and thermal properties of gelatin films at different degrees of glutaraldehyde crosslinking. Biomaterials, 22(8), 2001, pp. 763-768.

[12] Theerawitayaart, W., Prodpran, T., Benjakul, S., and Sookchoo, P. Properties of films from fish gelatin prepared by molecular modification and direct addition of oxidized linoleic acid. Food Hydrocolloids, 88, 2019, pp. 291-300.

[13] Emo Chiellini, Patrizia Cinelli, Elizabeth Grillo Fernandes, El-Refaie S. Kenawy, and Andrea Lazzeri. Gelatin-Based Blends and Composites. Morphological and Thermal Mechanical Characterization. (2001).

[14] Liu, Y., Deng, L., Zhang, C., Feng, F., and Zhang, H. Tunable Physical Properties of Ethylcellulose/Gelatin Composite Nanofibers by Electrospinning. Journal of Agricultural and Food Chemistry, 66(8), 2018, pp. 1907-1915.

[15] Li, J.-H., Miao, J., Wu, J.-L., Chen, S.-F., and Zhang, Q.-Q. Preparation and characterization of active gelatin-based films incorporated with natural antioxidants. Food Hydrocolloids, 37, 2014, pp. 166-173. 
[16] Yannas, I. V., and Tobolsky, A. V. Cross-linking of Gelatine by Dehydration. Nature, 215(5100), 1967, pp. 509-510.

[17] Formela, K., Hejna, A., Piszczyk, Ł., Saeb, M. R., and Colom, X. Processing and structureproperty relationships of natural rubber/wheat bran biocomposites. Cellulose, 23(5), 2016, pp. 3157-3175.

[18] Rose, J., Pacelli, S., Haj, A., Dua, H., Hopkinson, A., White, L., and Rose, F. Gelatin-Based Materials in Ocular Tissue Engineering. Materials, 7(4), 2014, pp. 3106-3135.

[19] Gill, Y. Q., Irfan, M. S., Saeed, F., Nadeem, M., and Ehsan, H. Silanized silica compatibilization of NBR/gelatin blends for the production of green rubber products. Journal of Elastomers \& Plastics, 2018.

[20] Riyajan, S.-A., and Teprak, A. A Novel Environmentally Friendly Biopolymer Product from Gelatin and Natural Rubber: Effect of Bagasse Fiber and Urea. Journal of Polymers and the Environment, 27(2), 2019, pp. 225-233.

[21] Flory, P. J., and Rehner, J. Statistical Mechanics of Cross-Linked Polymer Networks I. Rubberlike Elasticity. The Journal of Chemical Physics, 11(11), 1943, pp. 512-520.

[22] Boonkerd, K., Chuayjuljit, S., Abdulraman, D., and Jaranrangsup, W. Silica-Rich Filler for the Reinforcement in Natural Rubber. Rubber Chemistry and Technology, 85(1), 2012, pp. 1-13.

[23] Ellis, B., and Welding, G. N. Estimation, from Swelling, of the Structural Contribution of Chemical Reactions to the Vulcanization of Natural Rubber. Part II. Estimation of Equilibrium Degree of Swelling. Rubber Chemistry and Technology, 37(2), 1964, pp. 571-575.

[24] Chuaynukul, K., Prodpran, T., and Benjakul, S. Properties of thermo-compression molded bovine and fish gelatin films as influenced by resin preparation condition. International Food Research Journal, 22(3), 2015, pp. 1095-1102.

[25] Coran, A. Y. Vulcanization. In J. E. Mark, B. Erman, and F. R. Eirich (Eds.), Science and Technology of Rubber (p. 743). Elsevier Academic Press. (1994).

[26] Alwaan, I. M., Alftalawy, S. J. F., and Ali, H. H. Effect of gelatin starch on mechanical, morphology, structure and rheological properties of natural rubber. International Journal of Mechanical and Mechatronics Engineering, 17(4), 2017, pp. 17-26.

[27] Chaochai, T., Imai, Y., Furuike, T., Tamura, H., Chaochai, T., Imai, Y., Tamura, H. Preparation and Properties of Gelatin Fibers Fabricated by Dry Spinning. Fibers, 4(4), 2016, pp. 2-11.

[28] R. Gopa Kumar and Dr R. Rajesh. A Study on the Abrasion resistance, Compressive strength and Hardness of Banana-Fibre Reinforced Natural Rubber Composites. International Journal of Advanced Research in Engineering and Technology, 7(3), 2016, pp 42-55

[29] Gopakumar R and Dr. R. Rajesh, A Study on the Influence of Fibre Content on the Mechanical Properties of Natural Rubber Composites Reinforced with Banana Fibres Subjected to Various Surface Modifications, International Journal of Civil Engineering and Technology (IJCIET), Volume 8, Issue 6, June 2017, pp.186-195.

[30] Loui, T. R., Kumar, S. and Chandrabose, T.A. Comparative Study of the Effect of Treated Coir Fiber and Natural Rubber Modified Bitumen on Open Graded Friction Course Mixes. International Journal of Advanced Research in Engineering and Technology, 6(1), 2015, pp. 5669

[31] R. Ismail, A. Ibrahim, M. Rusop and A. Adnan, Determination of Mechanical Properties Natural Rubber Compounds Using Double Shear Test Pieces. International Journal of Civil Engineering and Technology, 9(8), 2018, pp. 37-43. 